\title{
Barriers and Facilitators to Uptake and Attendance of Secondary Cardiac Prevention Programmes for Indigenous New Zealanders
}

\author{
Kira G*, Kira A and Pokaia V \\ Massey University, New Zealand \\ *Correspondling author: Geoff Kira, School of Health \\ Sciences, Massey University, New Zealand
}

Received: October 06, 2021; Accepted: November 02, 2021; Published: November 09, 2021

\begin{abstract}
Aim: Cardiac Rehabilitation (CR) has good success in improving health outcomes after a heart event. There is poor enrolment and attendance of CR programmes worldwide, particularly for indigenous peoples, such as New Zealand (NZ) Māori. The present study aimed to provide in-depth interview information about barriers and facilitators of both enrolment and attendance in $\mathrm{CR}$, as well as identifying potential solutions.
\end{abstract}

Methods: Thirty-two semi-structured interviews with Māori referred to CR who either: did not enroll; enrolled but did not complete; and completed the programme. Interview topics were based on meta-syntheses and NZspecific information as well as suggested improvements. The transcripts were inductively analysed.

Results: Barriers specific to enrolment were inadequate timing or format of communication about CR. Time of day or day of week of sessions, and ability to find transportation to attend were barriers to attending. Group format and cultural focus were perceived as barriers to some, but facilitators for others (enrolment and attendance). Participants suggested ways to improve CR communication (enrolment), flexibility regarding content and timing of $\mathrm{CR}$, and, provision of transport (enrolment and attendance), and, increased cultural focus (enrolment and attendance).

Conclusions: Providing a greater variety and flexibility in CR programme design could potentially improve enrolment and attendance for indigenous and for non-indigenous clients. Offering CR sessions after hours, in locations that are easily accessible, having different formats such as: groups, individual versus online, or, indigenous- or European dominant-focus may mean that $\mathrm{CR}$ appeals to a larger group of CR patients.

Keywords: Cardiac rehabilitation; Secondary prevention; New Zealand Indigenous; Māori; Qualitative interviews

\section{Introduction}

Similar to many indigenous people worldwide, indigenous people of New Zealand (NZ) (Mãori) have a disproportionally high prevalence of Cardiovascular Disease (CVD), compared to their nonindigenous counterparts [1]. NZ Māori are hospitalized 1.5 more times than for non-Indigenous New Zealanders for CVD [2]. Cardiac Rehabilitation (CR) is a form of treatment that has good success in returning function and quality of life to patients after a CVD hospitalization [3,4]. Unfortunately, the system designed to reduce inequities is failing NZ Māori. For example, an audit of a regional CR service found that while $85 \%$ of Māori patients were referred to CR, only $37 \%$ took up (attended at least one session) and completed (attended at least four face to face sessions) outpatient CR [5]. Further research is needed in order to gain information about barriers and facilitators to uptake and attendance of CR for NZ Māori.

\section{International studies into barriers to uptake and attendance}

Very few international studies have investigated barriers and/or facilitators to CR uptake and/or attendance for indigenous people. A systematic review published in 2012 [6]. Identified only one published research study of barriers to $\mathrm{CR}$ participation for indigenous people (Aboriginal Australian people). This study identified that colonization and relatively young age were barriers to attending CR. Since that systematic review, only three more studies have been conducted into CR barriers with Aboriginal Australian people.[7-9] Two of the studies reported that Australian Aboriginal CR patients felt out of place because of their younger age, negative public health messages, the absence of culturally-appropriate practices [8], and a lack of indigenous HPs in CR [9]. Another study reported on the needs of Health Professionals (HPs) and allied HPs and found a lack of awareness of indigenous people's needs, need for increased cultural awareness and facilitation by indigenous HPs [7].

\section{Barriers to CR attendance for Māori}

We have only been able to find two published studies directly relating to uptake and attendance of CR for Māori patients. A national survey of patient data, which included but was not exclusive 
to Māori, was conducted of factors associated with CR uptake and attendance, with 916 CVD patients [10]. They found that lack of access to transport was negatively associated with and having previously attended CR was positively associated with CR attendance. Penney [5] conducted the most in-depth analysis of CR attendance for Māori. Ten interviews were conducted in the Auckland District Health Board (DHB) region, with Māori who took up CR but who did not complete. The main findings regarding barriers to completing $\mathrm{CR}$ were travel distance, work commitments and perception of need [13].

A further two studies investigated barriers to attending CVD services in general, but not with a specific focus on CR. Those studies found that barriers included ineffective communication by HPs and insufficient relationship building were barriers to attending CVD care [11], and, lack of referral, difficulty accessing the services or patients not thinking that the services were relevant enough to them [12].

\section{The present study}

Four studies have been conducted into barriers and facilitators for CR attendance of indigenous peoples. All these papers were conducted with Aboriginal Australian people. Only one report has specifically investigated barriers to attending CR for Māori people [5]. That study focused on barriers to continue attending, as opposed to taking up CR. we have not been able to find any published study that has investigated reasons to uptake AND continued CR attendance, nor identifying potential solutions, for Māori people. The aim of the study presented in this paper was to gathering in-depth information about barriers and facilitators for or against taking up and continuing attending CR and potential solutions for improving CR attendance, for Māori patients referred to outpatient CR. Furthermore, unlike previous studies, the present study included a wider range of participants: patients who did not take up CR, who took up CR but discontinued and those who completed CR.

\section{Methods}

In order to elicit in-depth information about uptake and attendance of $\mathrm{CR}$, semi-structured interviews based on predetermined topics drawn from literature $[5,6,13,14]$. Māori were at the centre of the study rather than the majority populous, NZ European [15]. Guidance and support to conduct the interviews was provided by local Māori councils (rūnanga) throughout the central region of New Zealand. Furthermore, the study was led and interviews undertaken by a Māori health scientist (GK). These factors provide an assurance that a Māori worldview would underpin the study conduct. Ethics for this study was obtained from Massey University Human Ethics Committee Southern B 13/77.

The recruitment took place from October 2014 to January 2015. Inclusion criteria were patients who self-identified as Māori and had been referred to CR in the previous two years from six DHBs in the central region of NZ (Whanganui, Hawkes Bay, Midcentral, Wairarapa, Hutt, and Capital and Coast). CR staff identified those that had or had not participated in CR and contacted the patients to gauge an initial interest to participate. Those patients' that expressed interest and consented had their contact details passed on to GK to undertake recruitment.

Patients who did not enrol in CR (uptake), enrolled but attended only 1-4 sessions (did not complete) and patients who enrolled and completed five or more sessions (complete) had attended and who did not attend CR were interviewed. Participants were also invited to include one (or more) support person/people in the interview. If the participant chose to include support people, patients and support person/people were interviewed together.

The interviews took place face-to-face at a location that was convenient and neutral for the interviewee. In a few cases, at the behest of the interviewee, the interview was held in a public place such as a café. As tikanga (Māori code of ethics) would dictate an initial period of exchanging personal information (mihi) took place and all patients interviewed were given a koha (gift) of NZD \$50 (US\$33, EUR€29) in the form of a grocery voucher. Interviews were recorded using an ICD-UX543F digital recording device (SONY) and notes were taken by the interviewer. Interviews lasted between 30 minutes to two hours.

The interviews were structured around a set of topics. The participants could talk about the topics in any order they chose. Interview topics were:

- Opinions on CR in general, CR uptake and continuation

- Provision of information: how, where and when, and by whom, the patients were provided with information relating to CR; where there any follow up information

- Why they (did not) enroll(ed) and attended CR

- Support that could have enable uptake and attendance

- $\quad$ Suggested improvements to CR in general and how to increase CR uptake and attendance

The interviews were transcribed. The transcripts were analysed using QSR NVivo $10^{\circ}$. The coding was conducted following a general inductive approach [16]. Both authors independently closely read the manuscripts. Using NVivo, both authors then created detailed themes. These themes where then refined to core themes as per the aim of the study, which were: reasons against taking up CR, reasons for taking up CR; reasons against continuing CR; reasons for continuing CR; and suggested improvements. Using the main aims of the study as a structure, that is reasons for or against taking up $\mathrm{CR}$, the detailed subthemes were discussed, to ensure that the quotes accurately represented the views of the participants.

In order to ensure that the reader can quickly ascertain key attributes relating to $\mathrm{CVD}$, such as age, gender and attendance at $\mathrm{CR}$, for each quote, the gender, age and attendance (and number of sessions attended) was noted. In the example below the participant was male, 53 years old and attended two CR sessions:

\section{$M, 53 y o$, attended [2] : <text >}

If the support person made the statement, the word "supp" was added. For example

\section{M, 53yo, attended [2], supp: <text>}

For the participants who did not attend CR, the number of sessions attended was changed to DNA (did not attend) as in the example below:

F, 66yo, DNA: <text > 


\section{Results}

A total of 43 patients were contacted for this study. Two patients declined to participate and nine were unable to be interviewed due to scheduling conflicts. Thirty-two patients consented and participated in a single interview. Thirty-nine percent $(n=12)$ included one or more support people in the interview. The average age of the patients was 61 years old and there were less women than men (Table 1).

\section{Uptake}

Twenty-one participants (66\%) had enrolled in CR and in their interview stated various reasons for taking up CR. In contrast, those that had not enrolled in CR had cited different reasons for not taking up CR. These reasons for or against uptake are discussed in detail in the next two sections.

Reasons for enrolment: For those who took up CR, the primary reason was to obtain more information about their disease.

$M, 53 y o$, attended [2]: I was pretty keen to go to the group too once I heard about it. Because it was education for me around heart disease and looking after yourself.

$M, 46 Y O, A T T E N D E D$ [7]: So I was really keen to go through the rehab and find out more about what was going on with me... I didn't really know what any of the heart disease or anything like that was.

One participant stated that a respected elder encouraging them to attend

M, 47yo, attended [3]: The other one is, the way I look at it, and I've had [CR uptake] explained to me by a couple of kaumātua [respected elder male], they say to me, "Boy, you're no use to your whannau [family] if you're not alive."

Another reason for attending was due to provision of transport.

M, 55YO, ATTENDED [5]: They [CR unit] have a van that goes around and picks people up if they can't get there.

Reasons against enrolments: The reasons participants provided for not taking up CR included communication issues, a lack of perceived want or need to attend and practical reasons.

Communication issues: There were comments about the lack of or inappropriate communication about CR.

Some patients reported not having been told about CR or if they had been provided with information, they did not remember or understand the communication.

M, 75yo, DNA, Sup: I'm not sure, Cardiac Rehabilitation programme, never heard of it... So I just thought ok, cardiac rehabilitation is just getting well.

M, 62YO, DNA: They might have [mentioned CR in hospital] but I wouldn't have a clue, I cannot remember.

One patient remembered being told about CR in hospital, but did not believe he was contacted about CR as an outpatient.

M, 51YO, DNA: In the hospital, they told me this is what will happen, you will probably get called up to come in to rehab... but never got called in.

How and when information about CR is communicated may
Table 1: Characteristics of participants.

\begin{tabular}{|c|c|c|c|}
\hline & Men $(n=21)$ & Women $(n=11)$ & Total $(n=32)$ \\
\hline & 21 & 11 & 32 \\
\hline \multicolumn{4}{|l|}{ Age } \\
\hline Average & 60 & 64 & 61 \\
\hline Min & 43 & 43 & 43 \\
\hline Max & 78 & 77 & 78 \\
\hline \multicolumn{4}{|l|}{ Attendance } \\
\hline $\begin{array}{l}\text { Completed (5 or more } \\
\text { sessions) }\end{array}$ & 8 & 5 & 13 \\
\hline Attended (1-4 sessions) & 5 & 3 & 8 \\
\hline Did Not Attend & 8 & 3 & 11 \\
\hline \multicolumn{4}{|l|}{ District health board } \\
\hline Capital and Coast & 6 & 0 & 6 \\
\hline Hawkes Bay & 5 & 2 & 7 \\
\hline Hutt Valley & 2 & 3 & 5 \\
\hline Midcentral & 2 & 3 & 5 \\
\hline Wairarapa & 3 & 2 & 5 \\
\hline Whanganui & 3 & 1 & 4 \\
\hline
\end{tabular}

*District Health Board: Regionally appointed institution in NZ that allocates healthcare resources.

affect the choice to take up CR. Shortly after heart surgery may not be the best time to provide information to patients about CR.

M, 75yo, DNA, Sup: Afterwards [the surgery] he is too out of it to listen to what somebody is saying.... He needs to get well first... maybe a follow up a week later to say this is a program that is available

Format of communication: Furthermore, a number of participants stated that the reading material was difficult to digest.

M, 75yo, DNA, Sup: Look how much information there is [in the information pack] I am not going to read all that ... See it [first page] has nothing here about there being a cardiac rehabilitation programme available.

M, yo, DNA: All those flash wordings on that bit of paper doesn't mean an iota to me... I don't know what I'm looking at.

M, 62YO, DNA: I'm not a very good reader, I get hōhā (upset) too quickly. And I think, yes I will do it when I get home and then as soon as I get home, that is it, file it in the rubbish bin. As soon as I don't understand anything that's it and I just lose it.

Practical reasons: There were also practical reasons why patients did not take up CR. These included a lack of available programmes in their area.

F, 60yo, DNA, Sup: We've got nothing here [CR] to my knowledge. Well if we have, I don't know about them. My new doctor hasn't said anything; the practice hasn't said anything; [CR Nurse] didn't say anything

Some participants were not financially or physically able to travel to attend $\mathrm{CR}$.

M, 62YO, DNA: All that travel and I couldn't drive or anything for a long time afterwards... I couldn't afford to go anywhere. I told my [CR] nurse that I wouldn't mind going but I have no money to go. 
F, 70YO, DNA: [if] it [CR] is within my reach and I am not going to be travelling.

M, 62YO, DNA: Something may just happen when I'm walking and traveling [to $C R$ ].

Lack of perceived need for uptake: Some participants stated that they were aware of but chose to not attend CR. Some participants felt that the information they had been provided with was sufficient for them to do the rehabilitation by themselves.

M, 71YO, DNA: I reckon I can do the recovery bit by myself. Group therapies and that don't turn me on...

They gave me all the books and that; what I've gotta do. All the information's there.

M, 63YO, DNA: I didn't (attend) because I knew the education I had been given was enough for me

Some participants reported feeling so good after the surgery that they did not feel a need to attend $C R$.

M, 67YO, DNA: When I came out of Wellington [after the heart surgery], I felt friggin' fantastic.

Unsuitable CR programme format: Another reason for choosing to not take up CR included an unsuitable format of CR sessions.

F, 66YO, DNA: I couldn't be bothered. I'm not trying to be horrible but they [CR] just don't tickle my fancy.

There was a lack of interest in group-therapy.

M, 71YO, DNA: I reckon I can do the recovery bit by myself. Group therapies and that don't turn me on.

M, 43YO, DNA: One of the problems I have with the groups [CR] is my age...I feel awkward [being so much younger than other clients] so I don't go... I know [that] angina is an old person's problem

\section{Attendance}

Some of the reasons for discontinuing were similar to reasons for not taking up, such as a perceived lack of relevant information, dislike of groups or practical reasons. However, there were also issues relating to institutionalised barriers where structural policies, procedures or processes did not promote attendance by Māori. In contrast, reasons for continuing to attend CR were similar to reasons for uptake, such as a desire to obtain information about their condition and practical support, but also reasons such as sharing with others, and a Pākehā format. These findings are discussed in more detail in the next two sections.

Reasons for attendance: People made a personal commitment to attending and felt that they owed it to themselves and others to go.

$M, 78 y o$, attended [6]: what I really wanted to do, was to make sure that I didn't take for granted the operation that I had ... I believed I owed them and myself the right to do everything they'd told us to do.

Obtaining information: One reason for continuing to attend CR was to obtain information about their condition. Patients went to CR to seek out information about heart disease in general and what they could do to avoid it happening again.

M, 47YO, ATTENDED [3]: I think it's a natural sort of curiosity of ours that when something happens to me... And, "What can I do to help with that next time?"

There was also a desire to obtain practical information about, for example, shaving.

F, 43YO, ATTENDED [6]: I was so freaking out because I was told that if you cut yourself it takes ages because of the clotting. So at one of our sessions I said ... 'what the heck do you use to shave your legs because I am frightened to go near a $b^{* *} d y$ razor'.

Some patients were unsure about attending CR, but once they realized that the information was useful, they continued going.

F, 77YO, ATTENDED [8]: I thought "No, this is good, this is helping me. This is going to help me".

It was also valuable for clinicians to take a plain language and less formal stance.

M, 78YO, ATTENDED [6]: One of the specialists sat down and said, "I want you to ask me questions... And don't be shy, any question. You might think it's silly. It may be the first time I've ever heard it, so please talk."

Group support: Patients reported that it was a relief to share about their heart condition with and/or listen to others in the group. They also liked talking with other people as a group.

M, 57YO, ATTENDED [6]: You had to say your name and what you had and you started talking about it and that sort of gave a big relief as well... Listening to what they have been through and what I have been through.

M, 46YO, ATTENDED [7]: And that was quite good because they were quite willing people to share their experiences.

M, 78YO, ATTENDED [6]: What I liked about it was the talks we had as a group.

Another reason for continuing with $\mathrm{CR}$ was the positive experience of sharing with, discussions and learning from other attendants.

F, 68YO, ATTENDED [21]: lots of discussion, lots of sharing, lots of learning and each time there's different people voice their concerns and their experiences and so from their experiences you learn ... The Tuesday sessions are so empowering.

M, 46YO, ATTENDED [7]: I think the thing was the older people had a lot of friends who had had problems, so their knowledge was a lot higher... There was quite a bit of information coming from some of the other attendees in terms of the ability to go to one of the local gyms franchises that have sort of like a heart rehab type thing.

Practical support: Practical support, such as transport provided to assist with attending appointments, enabled attending CR.

$M, 55 Y O, A T T E N D E D$ [5]: They [CR] have a van that goes around and picks people up if they can't get there.

M, 46YO, ATTENDED [7]: He [father] was really supportive... And he actually took me to the first couple of sessions.

Pākehā format: While lack of Māori involvement was an issue for some participants, others felt a Pākehā format suited them better. 
A few participants expressed that they felt more comfortable with Pākehā rather than Māori ways, and preferred non-Māori CR.

F, 67YO, ATTENDED [6]: I'm more Pākehā, sorry... My son would laugh... He once called me a potato, dark on the outside and white on the inside.

M, 46YO, ATTENDED [7]: I'm the white sheep of the family. I'm the only one that can't speak Te Reo. And my wife is Pākehā. So in terms of having a Māori-focused programme, it's not a big thing for me.

A participant specifically said that she did not want CR at a marae.

F, 67YO, ATTENDED [6]: I'm not keen on the Marae because to me it's completely foreign, I've probably only been once or twice in my life.

\section{Reason against attendance}

Institutionalised Barriers: No direct racism was reported by participants in CR, however participants reported structural barriers that primarily affected Māori. Some felt that there was inadequate Māori involvement in CR, both in terms of the HP's holding the CR and the patients attending $C R$.

M, 55yo, DNA: I'm a bit of a sook about Māori things. I always find it really neat when I'm there with a kaumätua and that, but they were just Pākehā (non-Māori) kaumātua.

M, 53yo, attended [2]: I was one of the youngest ones at the time I went, all the elderly European men... A lot of them were 60 and 70.

There was also a perceived lack of Māori spiritual practices in CR.

M, 47YO, ATTENDED [3]: when we look at the services that provide for these people [Māori] that are high risk, you don't have any tikanga [Māori conventions and protocols] in place.

M, 45YO, ATTENDED [3]: If we go back to our ancestors before they did any travelling they did the Karakia to appease with our Atua... you have to get those things down [in CR], and that's how I see it. And that's what I have been thinking about how to approach our people [for CR].

Lack of relevance: People also talked about that there wasn't any useful or relevant information specific to them.

M, 73yo, attended [1]: But to me I thought it was a waste of time because they told me nothing more than I already knew... to tell you the truth, I was $b l^{* *} d y$ bored

$M, 45 y o$, attended [3]: It was a generic thing for everybody.

Other participants stated that they stopped going because CR did not fit with them.

F, 43yo, attended [6]: I was the youngest one out of the lot and none of them had what I had... It was really hard to relate to. Like I could completely feel what was going on for them but I couldn't relate.

F, 55yo, attended [3]: A lot of the patients are a lot older than me, so it was more geared to sort of 70+ so I found it quite a bit boring

$F, 43 y o$, attended [6]: I went back at the beginning of another intake... It didn't click in for me.

Dislike of group therapy: There were some of comments relating to patients' dislike of group therapy. Some participants preferred to do CR on their own, rather than in a group. Another patient stated that she didn't like groups sharing.

F, 68yo, attended [1], Sup: I'm gonna do my own because I'll start walking and all that sort of thing.

F, 55yo, attended [3]: I think the last one that I went to was about heart patient support group or something and it just seemed to be a bit sad, sitting round and talking about how sad you all are... Yeah, it just seemed you're all going to talk about your operation forever more.

Returning to work: Some participants stated that they discontinued with CR because of returning to work. They also stated that because CR is usually held during day hours, it was not possible for them to attend because of a need to work.

$M, 45 y o$, attended [3]: I stopped going to the rehabilitation class after four weeks and went back to work

M, 46YO, ATTENDED [7]: The problem is it's [CR] during the day, when I'm working... So that was bit of a disappointment, in terms of I would have liked to have kept going to those, but being in the middle of the day it's just too hard.

\section{Suggestions for improving enrolment and/or attendance}

For some issues, participants made suggestions for how to improve uptake and attendance. The suggestions were predominantly relating to these main themes: improving communication, increase emphasis on Māori specific needs and practical improvements.

Enrolment-Improving communication: There were suggestions provided on how to improve communication about CR. A number of specific suggestions were made, such as putting information on posters on the wall in the pre-operative area.

M, 75YO, DNA: you sit there long enough waiting to get called so you read all the things on the wall. But if I had seen... cardiac rehabilitation programme I would have said, gee what is that?

A variety of formats were preferred for receiving information once they had arrived back at home. Some people preferred online information, such as email or internet.

F, 55yo, attended [3]: Oh email's probably the best for me.

F, 68YO, ATTENDED [21]: Oh nanny Google I love nanny Google.

M, 75yo, DNA: I should be able to go online and find out who is running this in [Location].

Whilst others did not use the internet at all and preferred other forms of communication.

M, 74YO, DNA: Sorry he can't turn the computer on.

F, 60YO, ATTENDED [6]: No I haven't got internet.

M, 67YO, ATTENDED [8]: Mail is alright. Sometimes I may not be home for a phone call and I'm no good on the internet

Enrolment and attendance: Increased Māori emphasis: A lot of participants suggested that an increased emphasis on Māori specific needs could improve uptake and attendance. There were suggestions that being able to talk to someone Māori, either a health professional or kaumatua, or having a Māori person represent them would 
improve $\mathrm{CR}$ uptake and attendance.

M, 51YO, ATTENDED [3]: one of the things that I felt would have really benefited me would have been being able to talk to somebody that was Māori.

F, 60yo, attended [6]: I wouldn't mind seeing more Māori practitioners dealing with things like that. Like a Mãori perspective of the medical team.

Participants also brought up the importance of support people, in terms of being able to bring a support person to CR sessions and also providing support for the support people.

F, 55yo, attended [3]: I think you might attract more Māori if you did, cos I notice that the ones that were there were all quite extrovert... a lot of people are quite whakama about that kind of thing [CR]. If they were able to bring someone with them that might attract more people.

M, 43YO, DNA: Allow me to bring them [wife and daughter] with me. The rehab said that my wife could come...

M, 55YO, DNA: Even if there's something you want to ask but you feel you can't. Like the [nanas] will step in and they did. You're going to overstep the boundaries if you ask certain questions but they don't care, they will just jump in and ask it for you.... The kaumatuas. That's why it is important we have marae-based.

There was a need to ensure that patients did not feel like the CR is seen as charity, or that the patients were a burden.

F, 55yo, attended [3]: And you know that our whānau do not like charity, and they do not like people feeling sorry for them, and they do not like being told how to live their lives.

Enrolment and attendance-Practical improvements: Participants made a number of suggestions for practical improvements of CR sessions. These suggestions included offering CR outside of working hours.

M, 46YO, ATTENDED [7]: Yeah, out of the nine to five, Monday to Friday slot would have been cool.

One participant stated that a running the CR later in the day, might suit some better.

M, 43YO, DNA: I have problems with mornings [due to sleep problems]... it takes me on average 2 hours to roll out of bed before I do anything... by 10-11 you are ready to go do something. Things take a bit longer... the programmes are a bit early for me. CR

One participant suggested more flexibility of when to start with

M, 55YO, ATTENDED [5]: I thought six weeks was too far away for me. I thought they would get me in within four weeks...

Another suggestion was to provide transport to attend CR.

F, 55yo, attended [3]: I always think of the [TV] ad with the cervical smear, and they pick them up in the van and they all go together. I think if you could find a way to do that.

\section{Discussion}

This study contributes new knowledge regarding patient views of CR that have the potential to improve enrolment and attendance. When and how information was provided was identified as a barrier to enrolment. Providing information in at least one alternative format or timing has the potential to improve enrolment. This is consistent with the review conducted by Neubeck et al [6]. Furthermore, time of day, day of week, location, or start date of CR course, were barriers to both enrolment and attendance. More variety and flexibility in both those areas could potentially improve enrolment and attendance across populations in general, but primarily for indigenous people. Other aspects were, based on individual preference, both barriers and facilitators for enrolment and attendance. For instance, while some participants reported the group format as a barrier to enrolling and attending, others reported it as a facilitator. Similarly, some participants reported that the European-dominant format of $\mathrm{CR}$ was adequate, however others reported it as a reason not to attend. Different from some colonised nations, NZ Māori have a bipartisan viewpoint as a result of inter-marriage and living in a colonial nation under English government. These findings suggest that some aspects of CR may need to be designed to meet individual needs, which was also reported by Angus et al [13]. Having different options of group or individual or online formats and indigenous- or Europeandominant focus may mean that $\mathrm{CR}$ is appealing to a larger group of CVD patients.

\section{Communication}

Neubeck et al. [6] identified that communication (as a service barrier), in general, by referrers and CR staff is poor and that this contributes to poor enrolments. Previous studies of CR utilization found that ineffective communication by HPs or lack of perceived referrals were reasons for not utilizing CR services [17-26]. Some patients in the present study indicated that they were not able to remember information about or being invited to attend CR. However, according to hospital records, all the participants in this study had been provided with information about CR and invited to attend.

The amount of written material was identified as a particular burden felt by patients. The strong emphasis on health literacy in contemporary healthcare indicates that this is an aspect that is slow to change. One patient pointed out that the discharge material didn't have any reference to CR or contact details of CR staff on the first page. In contrast, some participants who had enrolled and attended CR, pointed out times where they had received excellent communication which encouraged their participation. This may be indicative of individual variance in hospital experience and levels of literacy. At all times the level of health literacy should be aimed at the most effective means of communication based on the patients' needs.

This suggests that improvements may be needed to enable a wider appropriateness of communication: 1) follow-ups postdischarge to ensure that patients are sufficiently able to understand the information; 2) For patients under the influence of medication, post-surgical trauma, or stress that affects memory, repeat contact and reminders may be needed. 3) The written material that issued to patients on discharge, needs to be redressed to be brief and more easily understood by people who have limited or no heart care knowledge; 4) Providing information in electronic format, such as email, websites, smart phone apps, or social media; 5) Face-to-face hospital ward access by a CR representative, preferably Māori, to 
establish a relationship with the patients and pass on information could be advantageous to encouraging CR uptake; 6) posters on the ward walls or online information.

\section{Flexibility in CR timing and accessing CR location}

Many of the participants were of working age. This is similar to other reports, such as, Robson et al. who reported that, for people aged 45-64 years old, ischaemic heart disease was three times higher (male) and 4.39 times higher (female) for Māori compared to NZ European [2]. Moreover, Penney [5] also found that work commitments were a barrier to CR completion. CR in NZ is commonly held during business hours, a time of day that may be inconvenient for patients who need to work. Holding CR sessions outside of business hours and covering information aimed at patients who are still in working age, may enable and entice more Māori to enroll in and attend CR.

Common to the international literature [6], location difficulties, such as unavailability in the local area, being unable to travel to $\mathrm{CR}$ location or being unable to afford transport to attend CR also figured in this study. Most of the participants found that they were not allowed to drive in the first few weeks since their heart event. To complicate matters, whānau were unavailable to provide support because they were unlicensed, working, or living too far away.

There are pragmatic programmes that have addressed some of these issues. For example, a home-based programmes, such as the Heart manual or its modified NZ version, the Heart Guide Aotearoa (HGA), Manaaki Manawa are potential alternatives that address both timing and location barriers $[27,28]$.

Furthermore, a review suggested that providing transport to group-based therapy would be a useful factor to address difficulties in accessing the CR location [6]. In the indigenous context, where rapport is more important in many indigenous cultures than in their non-indigenous counterparts, free transport could promote a principle of tikanga (kotahitanga) - bringing the patients together as one. The group bond could be established early and also negate any feelings of being a burden on whānau or the health system.

\section{Individualized programmes}

Despite reviews highlighting that the individual preference of the patient should be reflected in their CR referral, the process of doing so hasn't been well-established $[27,29]$. In a small $(n=17)$ nonindigenous study Wingham et al. concluded that "understanding the factors that influence patient's choices may help professionals guide them to the most appropriate CR method and hence improve uptake" [30]. Certainly, alternatives to the traditional approaches are needed to meet the needs of patients [25,31]. Despite this data regarding individual preference for $\mathrm{CR}$ approach, there is little empirical evidence testing the concept on uptake [29]. This may be due to the associated cost of running two or more approaches or lack of qualified staff to resource programmes. In any case, future interventions should take note of this for further study. Although home-based interventions, such as Heart Guide Aotearoa (HGA) [28] and Manaaki Manawa [32], have attempted to address some of these barriers, this research highlights that patients' needs require more than one variation of current practices.

Māori centric or not: Some patients expressed concerns about lack of Māori and Māori focus involved in CR. The tikanga principle of whakawhanaungatanga (relationship building) between CR staff and patient was suggested and could be bridged by a Māori liaison, particularly an elder [11]. A liaison could fulfil a number tasks of such as patient confidant and act as public advocate for issues perceived by patients to be socially awkward or inappropriate (tapu), and providing equity in power balance (aroha ki te tangata) during visits to patients in hospital, attending CR, and follow up post-outpatient CR. Although DHB's do provide this service, the patients in this study indicated that they are not highly utilised in phase two CR (discharged patients) and that this point serves as evidence to redress this inequity. The liaison could assist in the instance where the patient preferred the generic approach to the Māori-responsive approach.

\section{Strength and Limitations}

Strengths of this study were that an indigenous population, New Zealand Māori, were recruited from multiple DHB regions, giving a broader view of Māori perspectives. Further, unlike most other publications on indigenous people's attendance in CR, this paper interviewed people who did not enrol, in addition to those who did enrol. For qualitative in-depth interviews, this study had a relatively large sample. An additional strength was the application of cultural protocol, tikanga, which governed how the participants were approached and addressed.

A limitation of this study is that, the results from this study, as with all qualitative research, has limited generalisability. However, given that there was overlap with previous work, the support for the patient views and their recommendations is promising. Another limitation is that it is possible that some people who did not take up CR also did not allow for their details to be forwarded to the research team, thereby excluding their views from the study.

\section{Conclusion}

This study has identified pragmatic recommendations for enhancing CR programmes which could potentially increase appeal of $\mathrm{CR}$ to a larger portion of indigenous and non-indigenous people. More variety and flexibility in terms of communication about CR, and, timing and accessibility to locations of CR sessions could potentially improve enrolment and attendance for all patients [6]. Moreover, some aspects were perceived as barriers by some patients while facilitators for others, which suggests that meeting individual needs is important in order to improve both enrolment and attendance. Offering CR sessions after hours, in locations easily accessible, having different options available such as: groups, individual versus online, or, indigenous- or European dominant-focus may mean that $\mathrm{CR}$ appeals to a larger group of CR patients. Future intervention research is needed to assess what aspects may be most effective in increasing appeal of CR.

\section{References}

1. Bramley D, Hebert $P$, Jackson R, Chassin M. Indigenous disparities in disease-specific mortality, a cross-country comparison: New Zealand, Australia, Canada, and the United States. N Z Med J. 2004; 117: 1-16.

2. Robson B, Harris R. Hauora: Maori Standards of Health IV. A study of the years 2000-2005. Health (San Francisco). Wellington: Te Roopu Rangahau Hauora a Eru Poomare. 2007.

3. Lawler P, Filion K, Eisenberg M. Efficacy of exercise-based cardiac rehabilitation post-myocardial infarction: a systematic review and metaanalysis of randomized controlled trials. Am Hear Journal2. 2011; 162: 571- 
584.

4. Dalal HM, Zawada A, Jolly K, Moxham T, Taylor RS. Home based versus centre based cardiac rehabilitation: Cochrane review and meta-analysis. $\mathrm{Br}$ Med J. 2010; 340: 5651.

5. Penney L. Whaia te manawa ora: Utilisation of Cardiac Rehabilitation Services by Maori in the Auckland District Health Board Area. Kerikeri. 2012.

6. Neubeck L, Freedman S Ben, Clark AM, Briffa T, Bauman A, Redfern J. Participating in cardiac rehabilitation: a systematic review and meta-synthesis of qualitative data. Eur J Prev Cardiol. 2012; 19: 494- 503.

7. DiGiacomo ML, Thompson SC, Smith JS, Taylor KP, Dimer L, Ali M , et al. "I don't know why they don't come": Barriers to participation in cardiac rehabilitation. Aust Heal Rev. 2010; 34: 452-457.

8. Taylor KP, Smith JS, Dimer L, Ali M, Wilson N, Thomas TR, et al. "You're always hearing about the stats death happens so often": new perspectives on barriers to Aboriginal participation in cardiac rehabilitation. Med J Aust. 2010; 192: 602.

9. Hayman NE, Wenitong M, Hall EM. Strengthening cardiac rehabilitation and secondary prevention for Aboriginal and Torres Strait Islander peoples. Med J Aust. 2006; 184: 485-486.

10. Doolan-Noble F, Broad J, Riddell T, North D. Cardiac rehabilitation services in New Zealand: access and utilisation. N Z Med J. 2004; 117: U955.

11. Kerr S, Penney L, Barnes HM, McCreanor T. Kaupapa Maori Action Research to improve heart disease services in Aotearoa, New Zealand. Ethn Health. 2010; 15: 15-31.

12. Penney L. New perspectives on heart disease management in Te Ta Tokerau : Māori and Health Practitioners Talk Final Report. 2006

13. Angus JE, King-Shier KM, Spaling MA, Duncan AS, Jaglal SB, Stone JA, et al. A secondary meta-synthesis of qualitative studies of gender and access to cardiac rehabilitation. J Adv Nurs. 2015; 71: 1758-1773.

14. Clark AM, King-Shier KM, Spaling MA, Duncan AS, Stone JA, Jaglal SB, et al. Factors influencing participation in cardiac rehabilitation programmes after referral and initial attendance: qualitative systematic review and metasynthesis. Clin Rehabil. 2013; 27: 948-959.

15. Cunningham C. Maori Development and Maori Advancement. Matariki. 2008 1: $49-58$.

16. Thomas DR. A General Inductive Approach for Analyzing Qualitative Evaluation Data. Am J Eval. 2006; 27: 237-246.

17. Banerjee AT, Grace SL, Thomas SG, Faulkner G. participation among Canadian South Asians: A qualitative study. Hear Lung J Acute Crit Care. 2010; 39: 494-503.
18. Dolansky MA, Moore SM. Cardiac Rehabilitation Programs Is it Time to Reinvent ? Older Adults' Views of. 2006; 32: 37-44.

19. Hird C, Upton C, Chesson RA. 'Getting back to normal': patients' expectations of cardiac rehabilitation. 2004; 90: 125-131.

20. Mead H, Andres E, Ramos C, Siegel B, Regenstein M. Patient Education and Counseling Barriers to effective self-management in cardiac patients: The patient's experience. Patient Educ Couns. 2010; 79: 69-76.

21. Tod AM, Lacey EA, Mcneill F, Tod A. 'I' m still waiting...': barriers to accessing cardiac rehabilitation services. 2002; 40: 421-431.

22. Jones MI, Greenfield S, Jolly K. Patients' experience of home and hospital based cardiac rehabilitation: A focus group study. Eur J Cardiovasc Nurs. 2009; 8: 9-17.

23. Grewal K, Leung YW, Safai MAP, Stewart DE. Access to Cardiac Rehabilitation among South- Asian Patients by Referral Method : A Qualitative Study. 2010; 35: 106-112.

24. Heid HG. Influences on Women's Participation in Cardiac Rehabilitation. 2004; 29: 116-121.

25. Grace SL, McDonald J, Fishman D, Caruso V. Patient Preferences for Homebased Versus Hospital-based Cardiac Rehabilitation. J Cardiopulm Rehabi Prev. 2005; 25: 24-29.

26. Jones M, Jolly K, Raftery J, Yh G. ' DNA ' may not mean ' did not participate ': a qualitative study of reasons for non-adherence at home- and centre-based cardiac rehabilitation. 2007; 24: 343-357.

27. Jolly K, Taylor RS, Lip GYH, Stevens A. Home-based cardiac rehabilitation compared with centre-based rehabilitation and usual care: a systematic review and meta-analysis. Int J Cardiol. 2006; 111: 343-351.

28. Eadie S, Tane M. Heart Guide Aotearoa, Reducing Inequalities in Cardiac Rehabilitation. Hear Lung Circ. 2010; 19: S262-S263.

29. Dalal HM, Zawada A, Jolly K, Moxham T, Taylor RS. Home based versus centre based cardiac rehabilitation: Cochrane systematic review and metaanalysis. BMJ. 2010; 340: 5631.

30. Wingham J, Dalal HM, Sweeney KG, Evans PH. Listening to patients: Choice in cardiac rehabilitation. Eur J Cardiovasc Nurs. 2006; 5: 289-294.

31. Thompson DR, Clark AM. Cardiac rehabilitation: into the future. Heart. 2009; 95: $1897-1900$

32. Henwood W, Moewaka Barnes H. Manaaki Manawa Evaluation -Final Report to Manaia Primary Health Organisation. Auckland; 2008. 